\title{
Fluorescence-guided surgical sampling of glioblastoma identifies phenotypically distinct tumour-initiating cell populations in the tumour mass and margin
}

\author{
SGM Piccirillo', S Dietz², B Madhu², J Griffiths², SJ Price ${ }^{3}$, VP Collins ${ }^{4}$ and C Watts ${ }^{*, 1,3}$ \\ 'Department of Clinical Neurosciences, Cambridge Centre for Brain Repair, University of Cambridge, Fonvie Site, Robinson Way, Cambridge CB2 OPY, UK; \\ ${ }^{2}$ Cancer Research UK, Cambridge Research Institute, Li Ka Shing Centre, Robinson Way, Cambridge CB2 ORE, UK; ${ }^{3}$ Division of Neurosurgery, \\ Department of Clinical Neurosciences, University of Cambridge, Addenbrooke's Hospital, Hills Road, Cambridge CB2 OQQ UK; ${ }^{4}$ Division of Molecular \\ Histopathology, Department of Pathology, University of Cambridge, Addenbrooke's Hospital, Hills Road, Cambridge CB2 OQQ, UK
}

BACKGROUND: Acquiring clinically annotated, spatially stratified tissue samples from human glioblastoma (GBM) is compromised by haemorrhage, brain shift and subjective identification of 'normal' brain. We tested the use of 5-aminolevulinic acid (5-ALA) fluorescence to objective tissue sampling and to derive tumour-initiating cells (TICs) from mass and margin.

METHODS: The 5-ALA was administered to 30 GBM patients. Samples were taken from the non-fluorescent necrotic core, fluorescent tumour mass and non-fluorescent margin. We compared the efficiency of isolating TICs from these areas in 5-ALA versus control patients. HRMAS 'H NMR was used to reveal metabolic alterations due to 5-ALA. We then characterised TICs for self-renewal in vitro and tumorigenicity in vivo.

RESULTS: The derivation of TICS was not compromised by 5-ALA and the metabolic profile was similar between tumours from 5-ALA patients and controls. The TICs from the fluorescent mass were self-renewing in vitro and tumour-forming in vivo, whereas TICs from non-fluorescent margin did not self-renew in vitro but did form tumours in vivo.

CONCLUSION: Our data show that 5-ALA does not compromise the derivation of TICs. It also reveals that the margin contains TICs, which are phenotypically different from those isolated from the corresponding mass.

British Journal of Cancer (2012) I 07, 462-468. doi:I0.1038/bjc.2012.27I www.bjcancer.com

Published online 21 June 2012

(c) 2012 Cancer Research UK

Keywords: 5-ALA; human glioblastoma; tumour margin; tumour-initiating cells

Human glioblastoma (GBM) is the most aggressive adult primary brain tumour. Conventional therapies provide minimal benefits and median survival is approximately 14 months (Stupp et al, 2005).

The GBM recurs within $2 \mathrm{~cm}$ of the resected tumour, despite chemotherapy and radiotherapy. This tumour invades the adjacent brain and it is impossible to surgically determine the extent of this infiltration. Thus, the tumour border, as determined surgically, is very subjective and is currently mainly based on the visual appearance of the tissue correlated with intra-operative neuronavigation and imaging. The recent development of fluorescenceguided surgical resection of high-grade glioma, including GBM, aims at assisting the surgeons in identifying tumour cells and has been demonstrated to increase tumour removal and improve progression-free survival (Stummer et al, 2000). Fluorescenceguided resection is based on the use of 5-aminolevulinic acid (5-ALA), an endogenous intermediate of the porphyrin biosynthesis pathway. It acts as a prodrug that is metabolised intracellularly, leading to the selective accumulation of the fluorescent molecule protoporphyrin IX (PpIX) in tumour cells (Stummer et al, 1998).

Peri-operative fluorescence allows objective discrimination of necrotic material $(\mathrm{N})$, which is non-fluorescent, tumour mass

*Correspondence: Dr C Watts; E-mail: cw209@cam.ac.uk Received 27 April 2012; revised 22 May 2012; accepted 23 May 2012; published online 21 June 2012
(T) which is fluorescent, and tumour margin (M), which is non-fluorescent (Roberts et al, 2011; Idoate et al, 2011). N and M tissues can be easily discriminated based on macroscopic evidence of necrotic material and the margin appearing macroscopically as normal tissue at the tumour border. The absence of fluorescence is a potential objective surgical end point for standardising the resection, and also facilitating interrogation of distinct tumour areas. In this context, it has also been recently reported that PpIX concentration is higher in areas of increasing malignancy in gliomas (Valdes et al, 2011) and that fluorescence-guided resection can be used to assist the evaluation of expression of Nestin and $\mathrm{Ki} 67$ at the tumour border and to study the tumour-brain tissue interface (Idoate et al, 2011).

In the last decade, it has been demonstrated that human brain tumours, in particular GBM, contain tumour-initiating cells (TICs) (Ignatova et al, 2002; Hemmati et al, 2003; Singh et al, 2003; Galli et al, 2004; Singh et al, 2004; Yuan et al, 2004) and it has been proposed that it is necessary to eradicate these cells in order to block tumour regrowth (Reya et al, 2001). More recently, it has been demonstrated that distinct TICs that have genetically diverged from a common ancestor co-exist in the same GBM (Piccirillo et al, 2009b) and may provide the basis for recurrence.

As 5-ALA helps to identify the high-grade malignant disease during surgery, we wanted to test if the use of 5-ALA could compromise derivation of TICs and could be used to identify TICs in M. 


\section{MATERIALS AND METHODS}

\section{Patient recruitment and sample collection}

The project received approval from the UK National Research Ethics Service and the University of Cambridge National Health Service Foundation Trust Research and Development department. All patients and imaging data sets were reviewed pre-operatively at the specialist Neuro-oncology multi-disciplinary team and subsequently seen in our dedicated research clinic (Guilfoyle et al, 2011). A total of 40 patients with a radiological diagnosis of GBM were recruited and written informed consent was obtained preoperatively. There were 23 men and 17 women. Mean age was 59.9 years at diagnosis (range 32-77) (see Supplementary Table 1).

To assess the impact of 5-ALA on TIC derivation, 10 patients were administered with 5-ALA (5-ALA + ve GBMs) (Medac, Stirling, UK) and 10 patients did not (5-ALA - ve GBMs). The 5-ALA was administered orally $\left(20 \mathrm{mg} \mathrm{kg}^{-1}\right.$ ) (Tonn and Stummer, 2008) $5 \mathrm{~h}$ before surgery. Samples were taken from $\mathrm{T}$ using image guidance to identify where the sample was taken. Each sample taken was divided in two parts: one part for cell derivation and other for histopathological analysis. Further, 20 patients were recruited for sampling and $\mathrm{N}, \mathrm{T}$ and $\mathrm{M}$ specimens were obtained from each.

Cytoreductive surgery and tissue sampling was performed using a Zeiss OPMI Pentero operating microscope (Zeiss, Welwyn Garden City, UK) with a xenon lamp providing a 405-nm light source for excitation (Zeiss) and a 620-710-nm bandpass filter for detection of PpIX fluorescence (Zeiss). 'Fluorescence' was defined as 'visible fluorescence using the operating microscope' as described above. The tissues collected corresponded to no, low, moderate and highly fluorescent material (levels $0,1,2$ and 3) as previously reported (Valdes et al, 2011). Because of the subjective nature of the 'low' and 'moderate' distinction during surgery, we adopted a binary approach: tissue was either visibly pink or it was not. Tissue was subsequently analysed accordingly. $\mathrm{N}$ and $\mathrm{M}$ were not visibly pink and $\mathrm{T}$ was visibly pink. This is a pragmatic approach that can be easily applied in the operating room.

\section{Cell-derivation and tumour-formation assay}

Primary culture, culture derivation and propagation were performed as previously described (Piccirillo et al, 2009b; Fael Al-Mayhani et al, 2009). Immunofluorescence assays were performed for the following markers: glial fibrillary acidic protein (GFAP), class III $\beta$-tubulin (Tuj1) and oligodendrocyte marker $(\mathrm{O} 4)$ were performed as described by (Piccirillo et al, 2009b).

All animal procedures were performed according to the Home Office UK guidelines. Intracerebral transplantation of $3 \times 10^{5} \mathrm{GBM}$ cells into the right striatum of 4-week-old Nod/Scid mice was performed as previously described (Piccirillo et al, 2009b). The GBM cells used for transplantation were either uncultured ('directly from patients') or propagated in vitro for two passages ('briefly cultured') in serum-free (SF) media before injection (Piccirillo et al, 2009b; Fael Al-Mayhani et al, 2009). Animals were killed when symptomatic.

\section{Real-time expression analysis of TICs from human GBM}

Total RNA was extracted from $\mathrm{T}$ and $\mathrm{M}$ cells from briefly cultured cells of three samples from 5-ALA + ve GBMs. TRIzol (Invitrogen, Paisley, UK) was used according to the manufacturer's instructions. Before the synthesis of the first-strand complementary DNA (cDNA), RNA was treated with DNase (Qiagen, Crawley, UK). The cDNA was synthesised from $5 \mu \mathrm{g}$ of total RNA using Random Primers (Invitrogen) and a Superscript III First-Strand Synthesis System for real-time PCR (RT-PCR) (Invitrogen). The RT-PCR for Ki67, Nestin, GFAP, Sox2 and Notch2 transcripts was performed using CFX96 RT-PCR (Biorad, Hemel Hempstead, UK), RT² qPCR
Primer Assay and $\mathrm{RT}^{2}$ SYBR Green qPCR Master Mix (SABiosciences, Qiagen, Crawley, UK) according to the manufacturer's instructions. The $18 \mathrm{~S}$ was used as the housekeeping reference. Relative expression quantification was performed by the $\Delta \Delta \mathrm{CT}$ method (Livak and Schmittgen, 2001). All the experiments were performed in triplicate and each triplicate was repeated three times.

\section{Histopathology}

Haematoxylin and Eosin (H\&E) staining was performed on $4 \mu \mathrm{m}$ formalin-fixed, paraffin-embedded GBM tissue, either derived from patients or from orthotopic transplantation of $3 \times 10^{5} \mathrm{GBM}$ cells as described above. For human tissues, a single neuropathologist analysed the H\&E tissue slides when blinded to the clinical, radiographical and pathological diagnoses derived from the main surgical specimen in each case.

Immunohistochemistry for GFAP was carried out according to the manufacturer's instruction (Dako, Stockport, UK).

\section{HRMAS ${ }^{1} \mathrm{H}$ NMR ANALYSIS OF TISSUE METABOLISM}

\section{Experimental procedure}

For metabolite analysis by using HRMAS ${ }^{1} \mathrm{H}$ NMR, tissues from 10 5-ALA + ve GBMs and 10 5-ALA - ve GBMs were collected in $\sim 50 \mathrm{mg}$ pieces into $2 \mathrm{ml}$ tubes, instantaneously transferred to dry ice (frozen $\mathrm{CO}_{2}$ ) and transported to the laboratory where each tube was transferred to liquid nitrogen for storage. The protocol published previously was followed (Opstad et al, 2008) with the following changes. On the day of assay, the tissue was cut into $\sim 10 \mathrm{mg}$ pieces on dry ice without thawing in a microbiological safety level 2 cabinet. A total of $10 \mu \mathrm{l}$ sodium formate $\left(100 \mathrm{mg} \mathrm{ml}^{-1}\right)$ was added as an internal standard for calibration of chemical shift to a disposable rotor insert. The tissue was inserted into the insert and the insert opening was closed with a screw cap. The total weight of the insert with the sample was noted. Then the insert was transferred to a $50 \mu$ l HRMAS rotor (made of $\mathrm{ZrO}_{2}$ ) (Bruker Biospin, Coventry, UK) and stored at $4{ }^{\circ} \mathrm{C}$ until the start of the measurement. The experiment was performed in a Bruker AVANCE NMR spectrometer (Bruker Biospin) operating at $600 \mathrm{MHz}$ for protons. HRMAS ${ }^{1} \mathrm{H}$ NMR analysis was performed using a $5-\mathrm{kHz}$ spinning frequency and at $4{ }^{\circ} \mathrm{C}$ temperature. The HRMAS ${ }^{1} \mathrm{H}$ NMR data acquisition included shimming and pulseangle calibration for each sample. Water-suppressed ${ }^{1} \mathrm{H}$ spectra were acquired for metabolite analysis with a repetition time of $8 \mathrm{~s}$ (total acquisition time $15 \mathrm{~min}$ ). A water-suppressed CPMG sequence (T2 filter times of 50, 100 and $200 \mathrm{~ms}$ ) was used to give lipid and macromolecule-free HRMAS ${ }^{1} \mathrm{H}$ NMR spectra. Unsuppressed water signal was used for metabolite quantitation.

\section{Pattern analysis using principal component analysis (PCA)}

The region between 0.5 and 4.5 p.p.m. of the HRMAS ${ }^{1} \mathrm{H}$ NMR spectrum was analysed using 0.01 p.p.m.-sized integration steps (socalled buckets). Two regions were excluded from the analysis (1.15-1.21 and 3.7-3.65 p.p.m.), as the signals found in these regions correspond to ethyl alcohol. The mean centred values of the buckets were analysed by unsupervised PCA and visualised in two-dimensional PCA maps. The score plot pictures the relationship of samples to one another according to the chosen principal components.

\section{Linear combination model}

Metabolite quantitation from HRMAS ${ }^{1} \mathrm{H}$ NMR spectra was performed by using LCModel (Provencher, 2001) with a basis set that had been used in an earlier study (Opstad et al, 2008). The unsuppressed tissue water signal from the ${ }^{1} \mathrm{H}$ NMR spectra was used to estimate absolute concentrations. The set of metabolites analysed included alanine, acetate, aspartate, choline, creatine, 
gamma aminobutyric acid, glucose, glutamine, glutamate, glycine, glycerophosphocholine, glutathione, inositol, lactate, leucine, lysine, $\mathrm{N}$-acetyl aspartate, $\mathrm{N}$-acetyl aspartylglutamate, phosphocholine, phosphorylethanolamine, scyllo-inositol and taurine. Additionally a number of lipid (Lip) and macromolecular (MM) peaks were analysed, wherein the number after Lip/MM corresponds to the chemical shift of the HRMAS ${ }^{1} \mathrm{H}$ NMR peak (e.g., Lip13a is identified by a lipid peak at 1.3 p.p.m.). The following lipids and macromolecules were analysed: Lip13a, MM14, Lip09b, MM09, Lip15, MM17, Lip205, MM205, MM225, MM32a, MM32b, MM30, Lip28b, Lip28a, MM12 and MM18.

\section{Statistical analysis}

Statistical analysis was performed using Microsoft Excel and SPSS (IBM, Portsmouth, UK). Normality was tested using the Kolmogorov-Smirnov test. Pairwise comparisons between $\mathrm{T}$ and $\mathrm{M}$ from the same GBMs were made using paired $t$-tests. An alpha of $<0.05$ ( $P$-value $<0.05)$ was considered significant. All error bars represent s.e.m.

\section{RESULTS}

The 5-ALA does not affect the isolation and propagation of TICs from human GBM

Using techniques for in vitro derivation and propagation of TICs previously reported (Galli et al, 2004; Piccirillo et al, 2009b; Fael AlMayhani et al, 2009), we compared the efficiency of isolation of TICs from $\mathrm{T}$ in 10 5-ALA + ve versus 5-ALA - ve GBMs. We first identified fluorescent tissue (Figure 1A) and we confirmed that it was tumour (Table 1 and Supplementary Figure 1) according to previous findings demonstrating that 5-ALA identifies solid tumour with $100 \%$ positive predictive value and that high concentration of PpIX strongly correlates with tissue malignancy (Valdes et al, 2011; Idoate et al, 2011). We have previously isolated TICs from $20 \mathrm{GBM}$ samples prior to the use of 5-ALA according to the Cambridge protocol previously described (Fael Al-Mayhani et al, 2009) and we adopted the same protocol to derive new TICs from 5-ALA + ve GBMs. We verified that 5-ALA does not affect the isolation (Figure 1B), propagation, clonogenic index (Figure 1C) and multipotency (Figure 1D) of TICs. Isolation of TICs in SF media (Fael AlMayhani et al, 2009) from 10 5-ALA + ve GBMs occurred with $100 \%$ efficiency. We observed sphere-forming capacity and clonogenicity in all the 10 analysed samples in SF media, as previously reported (Piccirillo et al, 2009b; Fael Al-Mayhani et al, 2009).

\section{Metabolic profiles of GBM samples from 5-ALA + ve and 5-ALA - ve patients reveal strong similarity}

As 5-ALA is an intermediate of the porphyrin biosynthesis pathway and is converted by the tumour cells into PpIX, we asked whether its use could alter the metabolism of tumour cells or lead to selection of tumour cells with active biosynthesis. Although studies on metabolic alteration induced by 5-ALA in tumours have not been described in the literature, it has been observed that metabolic diseases characterised by accumulation of 5-ALA can cause alteration of tryptophan metabolism (Lelli et al, 2008) and could be partly related to glucose metabolism disturbances (Lelli et al, 2005).

Therefore, we compared the metabolic profiles of TICs of 10 5-ALA + ve versus 10 5-ALA - ve GBMs by using HRMAS ${ }^{1} \mathrm{H}$ NMR spectroscopy. We performed the analysis using $\sim 10 \mathrm{mg}$ of tissue from the samples that were subsequently used for cell culture. We found no significant difference in the metabolite levels estimated in the ${ }^{1} \mathrm{H}$ NMR spectra (Figure $1 \mathrm{E}$ and Supplementary Table 2) or by PCA of the ${ }^{1} \mathrm{H}$ NMR data (data not shown) when the data from 5-ALA + ve GBMs was compared with those from 5-ALA - ve GBMs.

\section{The TICs isolated from 5-ALA + ve GBMs are tumorigenic}

The cardinal feature of TICs from GBM is that they develop tumours upon orthotopic injection into the brains of immunosuppressed animals (Vescovi et al, 2006). A bona fide TIC population is tumorigenic in vivo when cells are injected directly from a patient's sample or after a brief expansion in vitro in SF media (Piccirillo et al, 2006).

We verified the in vivo tumorigenicity of TICs isolated from four 5-ALA + ve versus four 5-ALA - ve GBMs by performing orthotopic injection into the brains of Nod/Scid mice. We found that TICs both 'directly from patients' and 'briefly cultured' retained tumorigenic potential, as demonstrated by tumour formation with an engraftment rate of $100 \%$ (Figures $1 \mathrm{~F}$, left and 2E). Histological analysis of these xenografts confirmed the presence of a $\mathrm{T}$ (Figure 1F, left) of glial nature, as demonstrated by GFAP immunoreactivity (Figure $1 \mathrm{~F}$, right). These data demonstrate that 5-ALA does not impair the tumorigenicity of TICs.

\section{Histopathological analysis and in vitro characterisation of non-fluorescent regions in 5-ALA + ve GBMs reveal different cell phenotypes}

The use of 5-ALA also provides us with a unique opportunity for objectively identifying and characterising malignant tissue. As previously reported (Roberts et al, 2011; Idoate et al, 2011), the $\mathrm{N}$ and $\mathrm{M}$ tissues in 5-ALA + ve GBMs do not fluorescence under the described peri-operative conditions for fluorescence imaging. We therefore compared $\mathrm{N}$ and $\mathrm{M}$ regions of the tumour in 20 5-ALA + ve GBMs.

We first established the absence of visible fluorescent material in $\mathrm{M}$ and $\mathrm{N}$ tissues using the OPMI Pentero operating microscope (Zeiss), and we confirmed by histological analysis the presence of necrotic material in $\mathrm{N}$ and a few scattered tumour cells in $\mathrm{M}$ (Table 1 and Supplementary Figure 1). Following the enzymatic dissociation of corresponding tissue, we found that in SF media, $\mathrm{N}$ consistently gave rise to primary cultures containing dead cells (Figure 2A, left), as expected from necrotic material. Conversely, viable cells could be found in $M$, which did not demonstrate selfrenewal (Figure 2A, right) and long-term proliferation in SF media with the current protocol (Figure 2B) (Piccirillo et al, 2009b; Fael Al-Mayhani et al, 2009). Sphere formation and clonogenicity was observed only in $10 \%$ of the cases for $\mathrm{M}$ tissue (data not shown). We evaluated the expression of the proliferation marker Ki67 on M versus $\mathrm{T}$ cells for three different samples by RT-PCR and we confirmed that the proliferative index of $\mathrm{M}$ cells was statistically significantly lower in comparison with $\mathrm{T}$ cells $(P<0.01, \mathrm{M}$ versus $\mathrm{T}$ cells, Figure 2C).

\section{Margin cells do not possess a 'stem-cell molecular signature' but retain tumour-initiating ability}

As it has been suggested that the margin of GBM represents an invasive niche where TIC maintenance is supported (Lathia et al, 2011), we performed a molecular characterisation of $M$ versus $\mathrm{T}$ cells to verify if $\mathrm{M}$ cells express markers of TICs.

We performed gene-expression analysis for stem-cell markers by RT-PCR. We selected the following markers: Nestin, GFAP, Sox 2 and Notch2, which have been previously shown to identify neural stem cells and to regulate their self-renewal and proliferation (Gaiano and Fishell, 2002; Sanai et al, 2004; Ferri et al, 2004; Shen et al, 2004; Vescovi et al, 2006) and have been retrieved in TICs from GBM (Hemmati et al, 2003; Piccirillo et al, 2006; Gangemi et al, 2009; Fan et al, 2010).

By comparing $\mathrm{M}$-cell gene expression with that of corresponding $T$ cells from the same tumour, we found that $M$ cells did not exhibit the same molecular signature typical of cells isolated from corresponding T $(P<0.05, \mathrm{M}$ versus $\mathrm{T}$ cells, Figure $2 \mathrm{D})$. Because of 
A

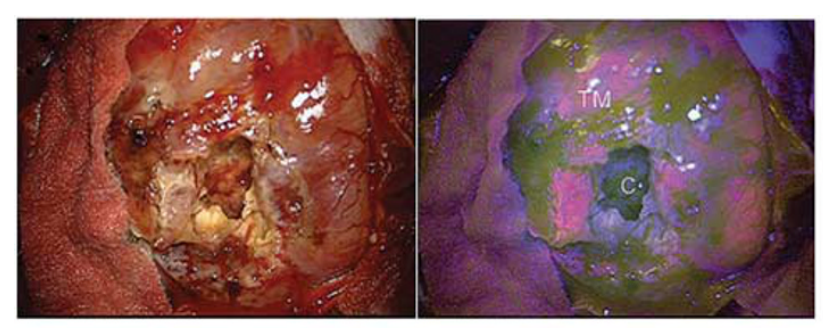

C

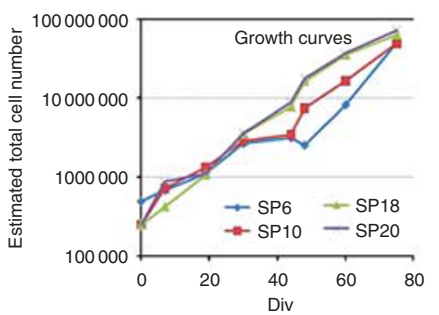

B

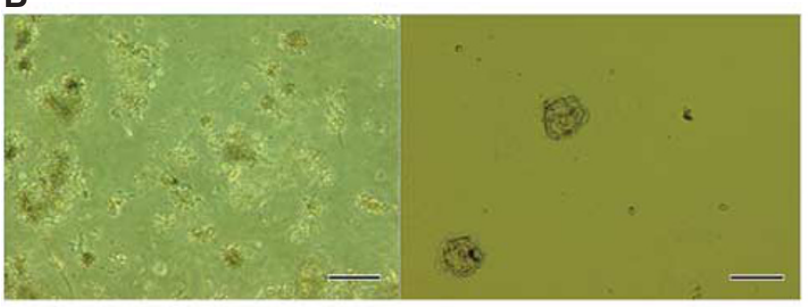

D

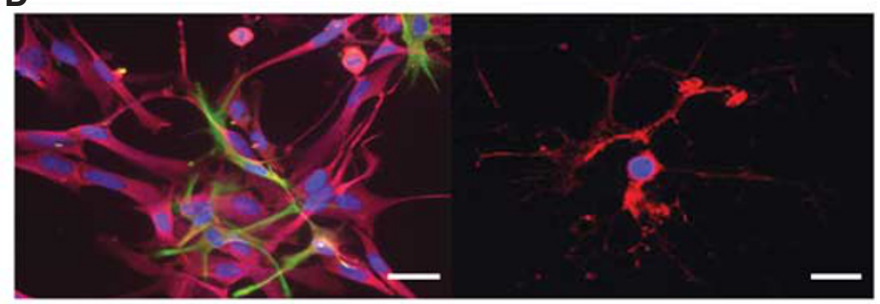

E

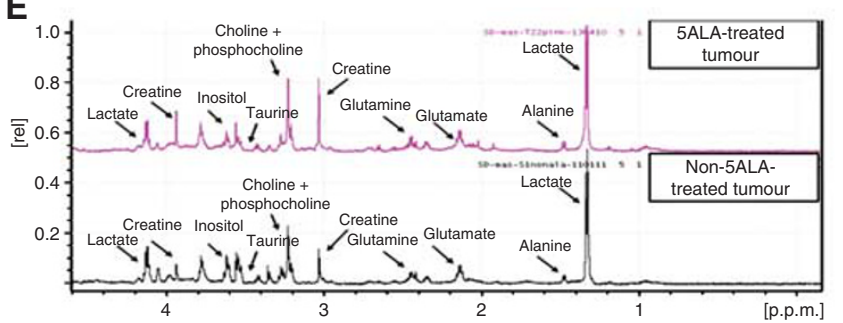

$\mathbf{F}$

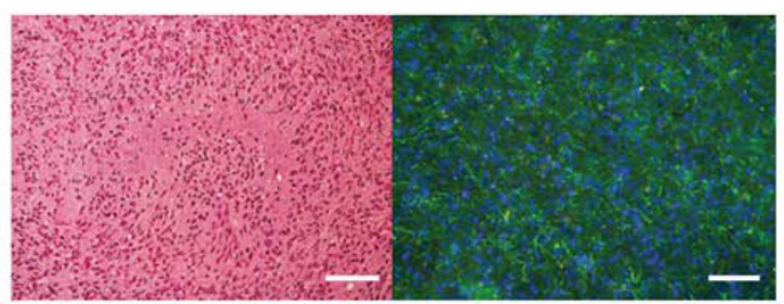

Figure I The TICs can be isolated using GBM samples obtained from 5-ALA-administered patients. (A) Human brain under the light (left) and the fluorescence microscope (right) during resection of GBM. The 5-ALA technology allows us to discriminate between three areas of disease in human GBM: fluorescent tumour mass $(T)$, non-fluorescent necrotic area $(N)$ and non-fluorescent margin $(M)$. (B) In vitro, cells isolated from T of 5-ALA + ve GBMs (left) and cultured in SF media grow as neurospheres (right) as previously reported (Piccirillo et al, 2009b; Fael Al-Mayhani et al, 2009) (Magnification $\times$ I00; scale bar, $50 \mu \mathrm{m})$. (C) Cells isolated from T of 5-ALA + ve GBMs are long-term expanding (left) and clonogenic as the cells isolated from T in 5-ALA - ve samples (right). Note that SP6 and SPI 8 TICs are derived from 5-ALA - ve GBMs and SPIO and SP20 TICs are established from 5-ALA + ve GBMs. (D) Upon in vitro differentiation, T cells from 5-ALA + ve GBMs resemble the phenotypes of normal neural stem cells by expressing astroglial and neuronal markers (GFAP, green and Tujl, fuchsia; left) and oligodendroglial-markers (O4, red; right) (Magnification $\times 400$; scale bar, $20 \mu \mathrm{m}$ ). (E) Representative HRMAS spectra of 5-ALA + ve GBM (top) and 5-ALA - ve GBM (bottom). Clearly visible peaks are annotated in both spectra. One example is shown as representative of 10 5-ALA + ve GBMs and 10 5-ALA - ve GBMs giving similar results. (F) Xenograft obtained upon injection of T cells of a 5-ALA + ve GBM. The H\&E staining reveals the presence of tumour (left) and GFAP immunoreactivity (green; right) confirms the glial nature of the tumour, counterstained with 4',6-diamidino-2-phenylindole dihydrochloride (Magnification $\times 200$; scale bar, $100 \mu \mathrm{m}$ ). Abbreviations: TM=tumour mass and C= core.

Table I Histological analysis confirms that fluorescence-guided resection identifies tumour mass, necrotic material and tumour margin

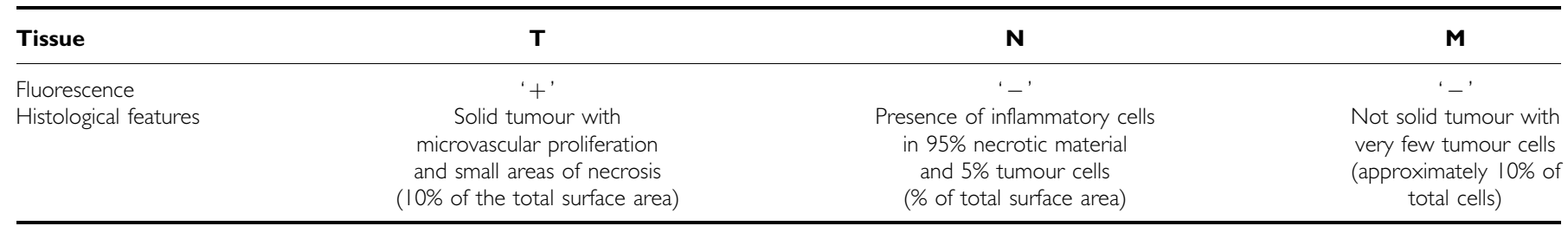

Histological analysis of T, $\mathrm{M}$ and $\mathrm{N}$ samples obtained from the same tumour confirmed that the cardinal features of glioblastoma were present in T. Conversely, $\mathrm{N}$ comprised mainly necrotic material and $M$ was composed of normal cells with a few tumour cells. 
A

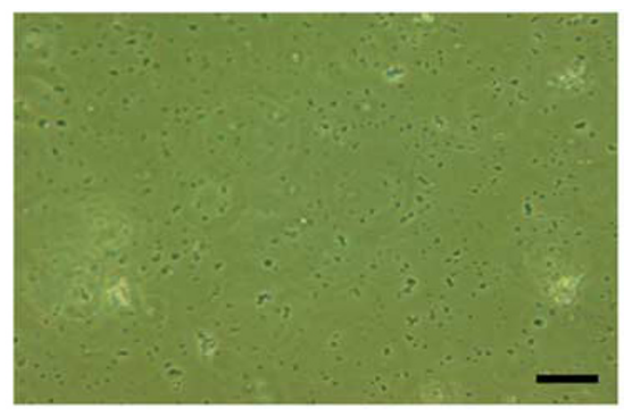

B

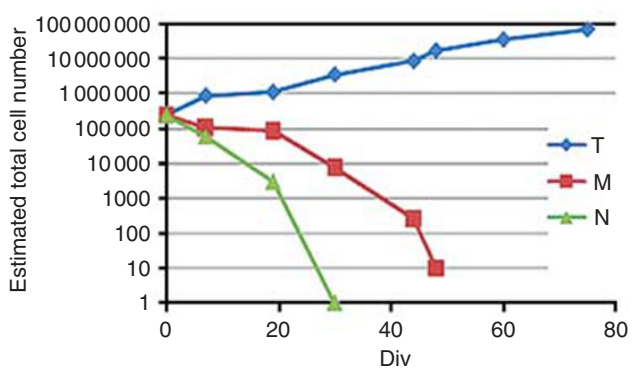

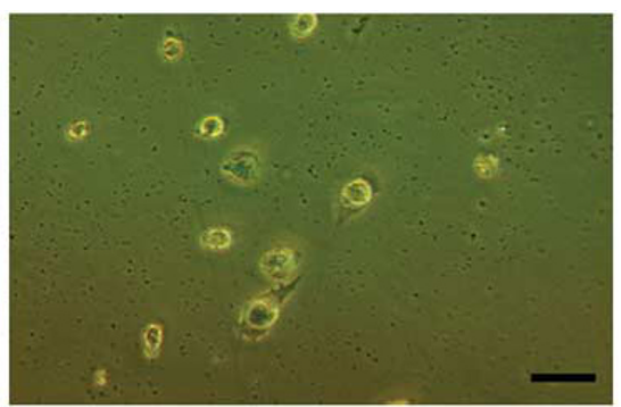

C $=S P 13 T=S P 13 M=S P 17 T=S P 17 M=S P 20 T=S P 20 M$

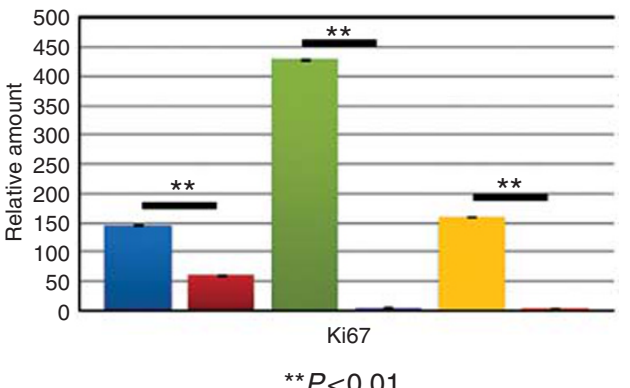

D
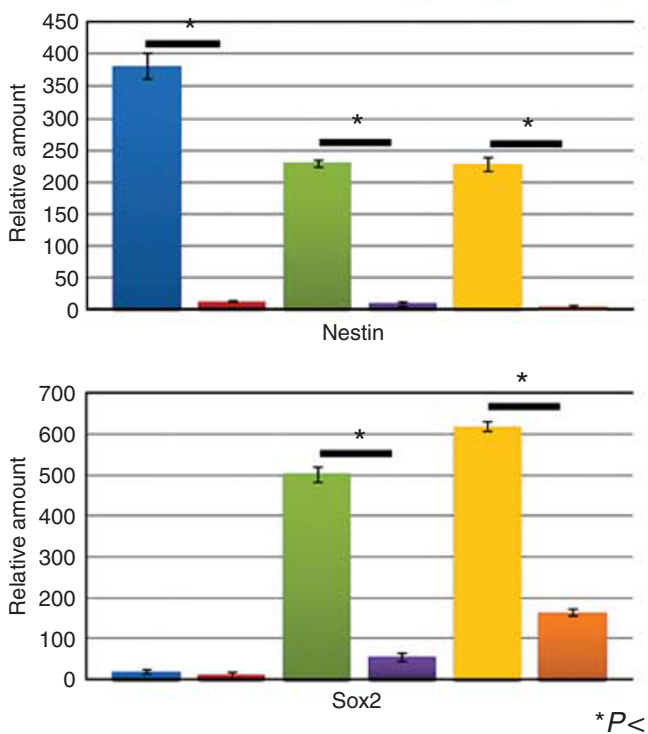
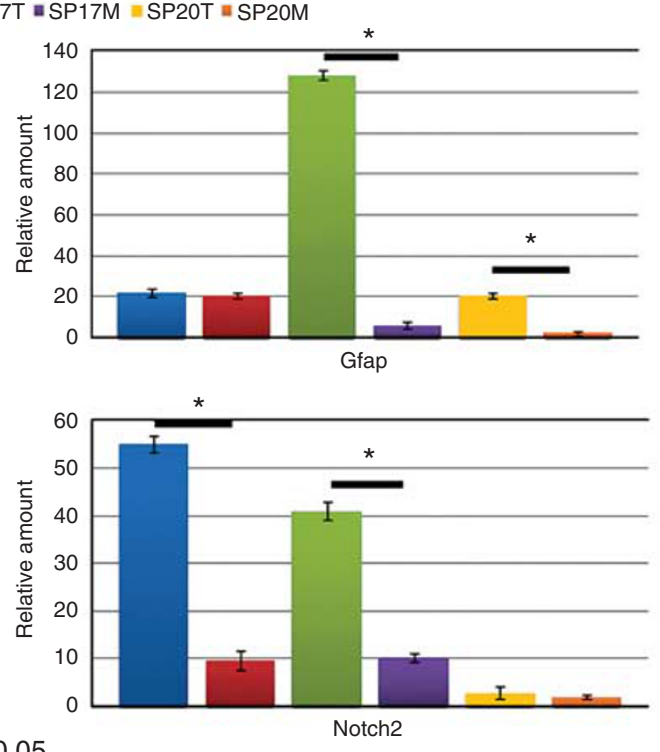

E

\begin{tabular}{|c|c|c|c|c|}
\hline Tumour origin & Sample & Tumour region & Tumours/injections & Engrafment rate (\%) \\
\hline Directly from patients & \multirow{3}{*}{ SP19 } & Mass & $3 / 3$ & $100 \%$ \\
\cline { 2 - 5 } & & Margin & $1 / 3$ & $33 \%$ \\
\cline { 2 - 5 } & \multirow{2}{*}{ SP24 } & Mass & $3 / 3$ & $100 \%$ \\
\cline { 3 - 5 } & \multirow{3}{*}{ Briefly cultured in vitro } & Margin & $2 / 3$ & $67 \%$ \\
\cline { 2 - 5 } & & Mass & $3 / 3$ & $100 \%$ \\
\cline { 2 - 5 } & \multirow{2}{*}{ SP20 } & Margin & $2 / 3$ & $67 \%$ \\
\cline { 3 - 5 } & & Mass & $3 / 3$ & $100 \%$ \\
\cline { 2 - 5 } & Margin & $2 / 3$ & $67 \%$ \\
\hline
\end{tabular}

Figure 2 Margin area in GBM contains a distinct population of TICs. (A) In vitro, primary cells isolated from N (left) and M (right) of 5-ALA+ ve GBMs do not grow in SF media (Magnification × 100; scale bar, $20 \mu \mathrm{m}$ ). (B) Growth-curve analysis show that only cells derived from the T are capable of long-term expansion. On the contrary, $\mathrm{N}$ cells die in a few passages. $M$ cells are not capable of long-term proliferation in these culture conditions. This analysis has been repeated on 20 sets of samples (T, M and N) giving similar results. (C) RT- PCR shows that the proliferation marker Ki67 is significantly less expressed in M cells in comparison with T cells $(n=3)$ in accordance to the growth-curve analysis shown in B. The number of data points included in each sample is 3 . (D) M cells show a poor 'stemcell molecular signature' in comparison with their corresponding T cells. Gene expression of Ki67, Nestin, Gfap, Sox2 and Notch2 has been evaluated using I8S as housekeeping $(n=3)$. The number of data points included in each sample is 3. (E) Table summarising the tumorigenic ability of $M$ versus $T$ cells in four samples. Cells were injected uncultured (directly from patients) or briefly cultured in vitro for two passages in SF media before injection into the brain of Nod/Scid mice. 
the differences in cell phenotype and molecular signature compared with TICs isolated from $\mathrm{T}$ samples, we hypothesised that $\mathrm{M}$ cells would not be tumorigenic in vivo.

Quite unexpectedly, orthotopic inoculation of $\mathrm{M}$ cells of four patients as cells obtained 'directly from patients' or 'briefly cultured in vitro' showed that $\mathrm{M}$ cells retain tumorigenicity in vivo (Figure $2 \mathrm{E}$ ). Only the $\mathrm{M}$ cells from sample SP19 revealed a very low tumorigenic potential with only one animal out of three developing a tumour mass, giving an engraftment rate of $33 \%$. This could be due to the fact that in this experiment $M$ cells were injected as a 'directly from patient' sample and may have contained very few or no malignant cells (Supplementary Figure 1). Further research will be needed to better characterise this area of the disease.

\section{DISCUSSION}

The use of 5-ALA has been extensively investigated as a means of performing a better surgical resection in patients diagnosed with GBM (Stummer et al, 2006). Recently, it has been reported that fluorescence-guided resection can permit the separation of malignant tissue from areas of putative healthy tissue at the histological level (Idoate et al, 2011). Fluorescence emission is also reported to correlate with histopathological markers that identify regions of increased malignancy in glioma (Valdes et al, 2011) and WHO grade (Roberts et al, 2011).

Our data reveal that 5-ALA does not compromise derivation of TICs and does not select for a subpopulation of metabolically distinct cells. The detection of visible fluorescence in $\mathrm{T}$ and absence of visible fluorescence in $\mathrm{N}$ and $\mathrm{M}$ regions allows pragmatic, real-time objective sampling of distinct tumour areas in GBM during surgery (our strategy is summarised in the cartoon presented as Supplementary Figure 2).

We started our analysis by showing that the fluorescent $\mathrm{T}$ contains TICs that can be efficiently derived by culture in SF media with high efficiency (Piccirillo et al, 2009b; Fael Al-Mayhani et al, 2009). We go on to show for the first time that the non-fluorescent $M$ contains a distinct cell population that is tumorigenic in vivo but is not self-renewing in vitro under the conditions used. This is in line with previous findings, suggesting that different TICs can co-exist in the same patient tumour (Piccirillo et al, 2009b) and that selfrenewal is not an essential pre-requisite for tumour formation in mouse models of high-grade gliomas (Barrett et al, 2012).

Our strategy is based on functional assays developed for the identification of TICs (Vescovi et al, 2006; Fael Al-Mayhani et al 2009). It is marker-independent, because no universal marker for human GBM is available to date (Piccirillo et al, 2009a). Our in vivo data are limited to the mouse-recipient strain, which we have been using for this study (Nod/Scid mice), and we are aware that the use of different mouse recipients can have an impact on the tumour-initiating capability of injected cells (Quintana et al, 2008). Nevertheless, our data do confirm that different TIC phenotypes can be identified in the same GBM using fluorescence-guided sampling of the $\mathrm{M}$ and $\mathrm{T}$.

More importantly, our results identify a non-self-renewing tumorigenic cell population in human GBM for the first time that requires further investigation. The identification of a phenotypically distinct TIC population in the $\mathrm{M}$ is potentially extremely important because this region corresponds to the residual disease that is subsequently exposed to genotoxic therapy and from which treatment-resistant recurrent disease emerges. Further investigation and molecular characterisation of this region will improve our understanding of the nature of 'residual disease' in GBM and hopefully translate into improvements in the treatment of patients.

\section{ACKNOWLEDGEMENTS}

This study was supported by the Evelyn Trust; the National Institute for Health Research Cambridge Biomedical Research Centre; the Higher Education Funding Council for England; the Royal College of Surgeons of Edinburgh; the European CommissionSeventh Framework Programme (Marie Curie Intra-European Fellowship to SGMP); and Cancer Research UK and Hutchison Whampoa Limited.

Supplementary Information accompanies the paper on British Journal of Cancer website (http://www.nature.com/bjc)

\section{REFERENCES}

Barrett LE, Granot Z, Coker C, Iavarone A, Hambardzumyan D, Holland EC, Nam HS, Benezra R (2012) Self-renewal does not predict tumor growth potential in mouse models of high-grade glioma. Cancer Cell 21(1): 11-24

Fael Al-Mayhani TM, Ball SL, Zhao JW, Fawcett J, Ichimura K, Collins PV, Watts C (2009) An efficient method for derivation and propagation of glioblastoma cell lines that conserves the molecular profile of their original tumours. J Neurosci Methods 176(2): 192-199

Fan X, Khaki L, Zhu TS, Soules ME, Talsma CE, Gul N, Koh C, Zhang J, Li YM, Maciaczyk J, Nikkhah G, Dimeco F, Piccirillo S, Vescovi AL, Eberhart CG (2010) NOTCH pathway blockade depletes CD133-positive glioblastoma cells and inhibits growth of tumor neurospheres and xenografts. Stem Cells 28(1): 5-16

Ferri AL, Cavallaro M, Braida D, Di Cristofano A, Canta A, Vezzani A, Ottolenghi S, Pandolfi PP, Sala M, DeBiasi S, Nicolis SK (2004) Sox2 deficiency causes neurodegeneration and impaired neurogenesis in the adult mouse brain. Development 131(15): 3805-3819

Gaiano N, Fishell G (2002) The role of notch in promoting glial and neural stem cell fates. Annu Rev Neurosci 25: 471-490

Galli R, Binda E, Orfanelli U, Cipelletti B, Gritti A, De Vitis S, Fiocco R, Foroni C, Dimeco F, Vescovi A (2004) Isolation and characterization of tumorigenic, stem-like neural precursors from human glioblastoma. Cancer Res 64(19): 7011-7021

Gangemi RM, Griffero F, Marubbi D, Perera M, Capra MC, Malatesta P, Ravetti GL, Zona GL, Daga A, Corte G (2009) SOX2 silencing in glioblastoma tumor-initiating cells causes stop of proliferation and loss of tumorigenicity. Stem Cells 27(1): 40-48
Guilfoyle MR, Weerakkody RA, Oswal A, Oberg I, Jeffery C, Haynes K, Kullar PJ, Greenberg D, Jefferies SJ, Harris F, Price SJ, Thomson S, Watts $C$ (2011) Implementation of neuro-oncology service reconfiguration in accordance with NICE guidance provides enhanced clinical care for patients with glioblastoma multiforme. Br J Cancer 104(12): 1810-1815

Hemmati HD, Nakano I, Lazareff JA, Masterman-Smith M, Geschwind DH, Bronner-Fraser M, Kornblum HI (2003) Cancerous stem cells can arise from pediatric brain tumors. Proc Natl Acad Sci USA 100(25): 15178-15183

Idoate MA, Diez Valle R, Echeveste J, Tejada S (2011) Pathological characterization of the glioblastoma border as shown during surgery using 5-aminolevulinic acid-induced fluorescence. Neuropathology 31(6): 575-582

Ignatova TN, Kukekov VG, Laywell ED, Suslov ON, Vrionis FD, Steindler DA (2002) Human cortical glial tumors contain neural stem-like cells expressing astroglial and neuronal markers in vitro. Glia 39(3): 193-206

Lathia JD, Heddleston JM, Venere M, Rich JN (2011) Deadly teamwork: neural cancer stem cells and the tumor microenvironment. Cell Stem Cell 8(5): 482-485

Lelli SM, San Martin de Viale LC, Mazzetti MB (2005) Response of glucose metabolism enzymes in an acute porphyria model. Role of reactive oxygen species. Toxicology 216(1): 49-58

Lelli SM, Mazzetti MB, San Martin de Viale LC (2008) Hepatic alteration of tryptophan metabolism in an acute porphyria model Its relation with gluconeogenic blockage. Biochem Pharmacol 75(3): 704-712

Livak KJ, Schmittgen TD (2001) Analysis of relative gene expression data using real-time quantitative PCR and the 2(-Delta Delta C(T)) Method. Methods 25(4): 402-408 
Opstad KS, Bell BA, Griffiths JR, Howe FA (2008) Toward accurate quantification of metabolites, lipids, and macromolecules in HRMAS spectra of human brain tumor biopsies using LCModel. Magn Reson Med 60(5): 1237-1242

Piccirillo SG, Binda E, Fiocco R, Vescovi AL, Shah K (2009a) Brain cancer stem cells. J Mol Med 87(11): 1087-1095

Piccirillo SG, Combi R, Cajola L, Patrizi A, Redaelli S, Bentivegna A, Baronchelli S, Maira G, Pollo B, Mangiola A, DiMeco F, Dalpra L, Vescovi AL (2009b) Distinct pools of cancer stem-like cells coexist within human glioblastomas and display different tumorigenicity and independent genomic evolution. Oncogene 28(15): 1807-1811

Piccirillo SG, Reynolds BA, Zanetti N, Lamorte G, Binda E, Broggi G, Brem H, Olivi A, Dimeco F, Vescovi AL (2006) Bone morphogenetic proteins inhibit the tumorigenic potential of human brain tumour-initiating cells. Nature 444(7120): 761-765

Provencher SW (2001) Automatic quantitation of localized in vivo $1 \mathrm{H}$ spectra with LCModel. NMR Biomed 14(4): 260-264

Quintana E, Shackleton M, Sabel MS, Fullen DR, Johnson TM, Morrison SJ (2008) Efficient tumour formation by single human melanoma cells. Nature 456(7222): 593-598

Reya T, Morrison SJ, Clarke MF, Weissman IL (2001) Stem cells, cancer, and cancer stem cells. Nature 414(6859): 105-111

Roberts DW, Valdes PA, Harris BT, Fontaine KM, Hartov A, Fan X, Ji S, Lollis SS, Pogue BW, Leblond F, Tosteson TD, Wilson BC, Paulsen KD (2011) Coregistered fluorescence-enhanced tumor resection of malignant glioma: relationships between delta-aminolevulinic acid-induced protoporphyrin IX fluorescence, magnetic resonance imaging enhancement, and neuropathological parameters. Clinical article. J Neurosurg 114(3): 595-603

Sanai N, Tramontin AD, Quinones-Hinojosa A, Barbaro NM, Gupta N, Kunwar S, Lawton MT, McDermott MW, Parsa AT, Manuel-Garcia Verdugo J, Berger MS, Alvarez-Buylla A (2004) Unique astrocyte ribbon in adult human brain contains neural stem cells but lacks chain migration. Nature 427(6976): 740-744

Shen Q, Goderie SK, Jin L, Karanth N, Sun Y, Abramova N, Vincent P, Pumiglia K, Temple S (2004) Endothelial cells stimulate self-renewal and expand neurogenesis of neural stem cells. Science 304(5675): 1338-1340

Singh SK, Clarke ID, Terasaki M, Bonn VE, Hawkins C, Squire J, Dirks PB (2003) Identification of a cancer stem cell in human brain tumors. Cancer Res 63(18): 5821-5828
Singh SK, Hawkins C, Clarke ID, Squire JA, Bayani J, Hide T, Henkelman RM, Cusimano MD, Dirks PB (2004) Identification of human brain tumour initiating cells. Nature 432(7015): 396-401

Stummer W, Novotny A, Stepp H, Goetz C, Bise K, Reulen HJ (2000) Fluorescence-guided resection of glioblastoma multiforme by using 5-aminolevulinic acid-induced porphyrins: a prospective study in 52 consecutive patients. J Neurosurg 93(6): 1003-1013

Stummer W, Pichlmeier U, Meinel T, Wiestler OD, Zanella F, Reulen HJ (2006) Fluorescence-guided surgery with 5-aminolevulinic acid for resection of malignant glioma: a randomised controlled multicentre phase III trial. Lancet Oncol 7(5): 392-401

Stummer W, Stocker S, Wagner S, Stepp H, Fritsch C, Goetz C, Goetz AE, Kiefmann R, Reulen HJ (1998) Intraoperative detection of malignant gliomas by 5 -aminolevulinic acid-induced porphyrin fluorescence. Neurosurgery 42(3): 525-526

Stupp R, Mason WP, van den Bent MJ, Weller M, Fisher B, Taphoorn MJ, Belanger K, Brandes AA, Marosi C, Bogdahn U, Curschmann J, Janzer RC, Ludwin SK, Gorlia T, Allgeier A, Lacombe D, Cairncross JG, Eisenhauer E, Mirimanoff RO (2005) Radiotherapy plus concomitant and adjuvant temozolomide for glioblastoma. $N$ Engl J Med 352(10): 987-996

Tonn JC, Stummer W (2008) Fluorescence-guided resection of malignant gliomas using 5-aminolevulinic acid: practical use, risks, and pitfalls. Clin Neurosurg 55: 20-26

Valdes PA, Kim A, Brantsch M, Niu C, Moses ZB, Tosteson TD, Wilson BC, Paulsen KD, Roberts DW, Harris BT (2011) \{delta\}-aminolevulinic acidinduced protoporphyrin IX concentration correlates with histopathologic markers of malignancy in human gliomas: the need for quantitative fluorescence-guided resection to identify regions of increasing malignancy. Neuro Oncol 13(8): 846-856

Vescovi AL, Galli R, Reynolds BA (2006) Brain tumour stem cells. Nat Rev Cancer 6(6): 425-436

Yuan X, Curtin J, Xiong Y, Liu G, Waschsmann-Hogiu S, Farkas DL, Black $\mathrm{KL}, \mathrm{Yu}$ JS (2004) Isolation of cancer stem cells from adult glioblastoma multiforme. Oncogene 23(58): 9392-9400

cC)(i) (2) This work is licensed under the Creative Commons BY NC SA Attribution-NonCommercial-Share Alike 3.0 Unported License. To view a copy of this license, visit http:// creativecommons.org/licenses/by-nc-sa/3.0/ 